\title{
A Pilot Study Using Asynchronous Case Discussion and Reflection to Provide Interprofessional Education to Physician Assistant and Physical Therapy Students
}

\author{
Erin McCallister \\ Louisiana State University Health Sciences - Shreveport, emadar@lsuhsc.edu \\ Emily Weidman-Evans \\ Louisiana State University Health Sciences - Shreveport, eevans@lsuhsc.edu
}

Follow this and additional works at: https://nsuworks.nova.edu/ijahsp

Part of the Educational Methods Commons, Medicine and Health Sciences Commons, and the Online and Distance Education Commons

This Manuscript has supplementary content. View the full record on NSUWorks here: https://nsuworks.nova.edu/ijahsp/vol19/iss1/12

\section{Recommended Citation \\ McCallister E, Weidman-Evans E. A Pilot Study Using Asynchronous Case Discussion and Reflection to Provide Interprofessional Education to Physician Assistant and Physical Therapy Students. The Internet Journal of Allied Health Sciences and Practice. 2021 Jan 01;19(1), Article 12.}

This Manuscript is brought to you for free and open access by the College of Health Care Sciences at NSUWorks. It has been accepted for inclusion in Internet Journal of Allied Health Sciences and Practice by an authorized editor of NSUWorks. For more information, please contact nsuworks@nova.edu. 


\title{
A Pilot Study Using Asynchronous Case Discussion and Reflection to Provide Interprofessional Education to Physician Assistant and Physical Therapy Students
}

\begin{abstract}
Purpose: The purpose of this study was to examine the effects an asynchronous interprofessional education (IPE) activity had on graduate healthcare students' beliefs regarding IPE, as measured by the Readiness for Interprofessional Learning Scale (RIPLS). Methods: All first-year physician assistant and physical therapy students participated in a collaborative four-week online case discussion. Students who consented to participate in the research component filled out a pre- and post-activity RIPLS questionnaire. Responses were matched by an individualized, student-generated number to protect students' identity. Only matched scores were analyzed. Results: The total score as well as the Teamwork and Professional Identity sub-scales were analyzed for pre-post changes using the paired t-test. The Roles and Responsibilities sub-scale was analyzed using the Wilcoxon signed rank test, due to a non-normal data distribution. A significant change $(a=0.05)$ in score was found only in the Roles and Responsibilities sub-scale. Secondary outcomes indicate that a high proportion of the students felt the objectives of the activity were met. Conclusions: Significant changes were found on only one sub-scale of the RIPLS. Therefore, asynchronous IPE delivery does not change graduate healthcare students' readiness for IPE. The participants felt the activity met its objectives, which indicates that asynchronous IPE delivery may be a viable technique in this population. Future studies should examine the difference between asynchronous and live IPE on the outcomes noted in this pilot study.
\end{abstract}

\section{Author Bio(s)}

Erin McCallister, PT, DPT, COMT is an Instructor of Physical Therapy in the LSU Health Shreveport School of Allied Health Professions in Shreveport, LA. She is also a Board-Certified Clinical Specialist in Orthopaedic Physical Therapy.

Emily Weidman-Evans, Pharm.D, BC-ADM, CPE is a Professor in the Physician Assistant program in the LSU Health Shreveport School of Allied Health Professions in Shreveport, LA. She serves as the programs Director of Assessment and holds a faculty appointment in the Department of Family Medicine. 


\title{
TIAHSP
}

The Internet Journal of Allied Health Sciences and Practice

Dedicated to allied health professional practice and education

Vol. 19 No. 1 ISSN 1540-580X

\section{A Pilot Study Using Asynchronous Case Discussion and Reflection to Provide Interprofessional Education to Physician Assistant and Physical Therapy Students}

\author{
Erin McCallister \\ Emily Weidman-Evans \\ Louisiana State University - Shreveport \\ United States
}

\begin{abstract}
Purpose: The purpose of this study was to examine the effects an asynchronous interprofessional education (IPE) activity had on graduate healthcare students' beliefs regarding IPE, as measured by the Readiness for Interprofessional Learning Scale (RIPLS). Methods: All first-year physician assistant and physical therapy students participated in a collaborative four-week online case discussion. Students who consented to participate in the research component filled out a pre- and post-activity RIPLS questionnaire. Responses were matched by an individualized, student-generated number to protect students' identity. Only matched scores were analyzed. Results: The total score as well as the Teamwork and Professional Identity sub-scales were analyzed for pre-post changes using the paired t-test. The Roles and Responsibilities sub-scale was analyzed using the Wilcoxon signed rank test, due to a non-normal data distribution. A significant change $(\alpha=0.05)$ in score was found only in the Roles and Responsibilities sub-scale. Secondary outcomes indicate that a high proportion of the students felt the objectives of the activity were met. Conclusions: Significant changes were found on only one sub-scale of the RIPLS. Therefore, asynchronous IPE delivery does not change graduate healthcare students' readiness for IPE. The participants felt the activity met its objectives, which indicates that asynchronous IPE delivery may be a viable technique in this population. Future studies should examine the difference between asynchronous and live IPE on the outcomes noted in this pilot study.
\end{abstract}

Keywords: interprofessional care, collaborative learning, online, RIPLS 


\section{INTRODUCTION}

The World Health Organization (WHO) has identified interprofessional education (IPE) as an important component of developing a healthcare work force that can work together in a collaborative manner. The WHO further defined IPE as occurring "when students from two or more professions learn about, from, and with each other to enable effective collaboration and improve health

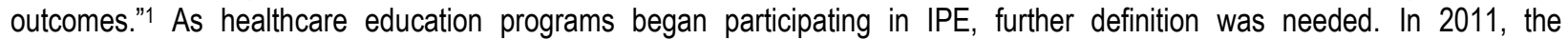
Interprofessional Education Collaborative (IPEC), composed of six national associations of schools of the health professions (medical, osteopathic, dental, pharmacy, public health and nursing), released their core competencies for interprofessional collaborative practice. These include four overarching domains: values/ethics for interprofessional practice, roles/responsibilities, interprofessional communication, and teams/teamwork. ${ }^{2}$

Throughout their clinical experiences, healthcare students are exposed to a variety of other healthcare professionals. Meaningful interprofessional education experiences are mandated by the accrediting bodies for the Physician Assistant (PA) and Physical Therapy (PT) programs. ${ }^{3,4}$ However, students at institutions' school of allied health professions traditionally have had limited contact with allied health students from other disciplines during their didactic training, with the exception of attending lectures with other students. Studies have shown that merely attending class with students from other disciplines does not promote interprofessional education: students must interact in a meaningful way to solve problems in order to prepare for collaborative practice.5,6

While IPE is desirable and necessary from an educational standpoint, the literature details numerous challenges faced when implementing IPE experiences. Aside from student attitudes, physical space and time within the program are often cited as barriers to carrying out IPE. . $^{-12}$ Therefore, the investigators sought to develop a means to overcome these two major challenges while still allowing meaningful interaction between students. The proposed solution was to offer the entire IPE experience in an "online classroom" (asynchronous) environment, with moderators to encourage communication and collaboration between the students.

The primary purpose of this pilot study was to investigate if providing IPE opportunities asynchronously changed student responses on the Readiness for Interprofessional Learning Survey (RIPLS). The secondary purpose was to determine if asynchronous IPE could adequately achieve learning objectives crafted based on the four IPE domains.

\section{METHODS}

First year PT students (37 total) and first year PA students (39 total) both enrolled in their second semester were eligible to participate in the study. A four-week, mandatory IPE activity was scheduled for the cohort of eligible students. However, the research component was voluntary, and study participation was not tied to grades for either profession. This study was approved by the Louisiana State University Health Sciences Center-Shreveport Institutional Review Board. The protocol adhered to the Helsinki Declaration to protect participants' rights. PA and PT students were selected due to the likelihood of the two professions collaborating outside of the didactic environment as well as agreement in scheduling and courses taken between the two student bodies.

Prior to week one of the activity, a faculty member not associated with the courses in which the activity was to take place emailed a recruitment letter explaining the purpose of the exercise and the research component of the activity. To maintain student anonymity, the recruitment letter asked each student to generate a unique four-number personal identification number (PIN) to be used for the research component. The PIN was used to enter responses to the pre- and post-activity questionnaires both of which were in Google Forms. The recruitment letter reinforced that the research portion was voluntary, and had an informed consent portion for those who wished to participate. After a student indicated they wished to participate in the research, they were directed to fill out the pre-activity RIPLS. Please see Appendix 1 to view the RIPLS.

The IPE experience consisted of four one-week modules that taught and assessed three of the four core domains: professional roles and responsibilities, teamwork, and communication. The weekly activities are shown below:

- Week one: Discussion of professional curricula and training and roles/responsibilities.

- Week two: Dissemination of diabetic wound case. Development of diagnosis. Compare and contrast between professions.

- Week three: Development of a treatment plan. Compare and contrast between professions.

- Week four: Prepare documentation of patient "encounter". Compare and contrast between professions (including others that were provided, including nursing, pharmacy, and a certified diabetes educator).

Students were placed in randomly assigned Moodle groups containing an equal distribution of PA and PT students in each group. A guiding scenario with questions was posed to the students at the start of each week. Each group was instructed to discuss 
portions of the scenario and reply to the posted questions as well as the questions posed by their fellow students. All discussions took place on Moodle, with no live meetings regarding the IPE activity between or within the student groups.

Both authors of this study monitored the discussion boards weekly and facilitated questions by highlighting important information, asking clarifying questions, or posing questions to prompt the students to examine a different facet of the weekly discussion. The authors of the study were both familiar with the learning objectives of the weekly activities and used this knowledge to help shape the student discussions to help meet the objectives. Formal evaluation of the learning objectives was not made until the students responded to the post-activity survey to avoid biasing the moderators' attitudes.

Each student was expected to participate in at least two of the four weekly discussions hosted on Moodle, and turn, in a reflection on the topic covered each week for class credit. Following week four of the IPE activity, all students were sent an email collecting the post-activity RIPLS score as well as student opinions on the activity. Students were asked to re-enter their PIN from the pretesting questionnaire. Only matched pre-post scores were used for statistical analysis.

\section{Data Analysis}

Outcome data was collected on student response to the RIPLS as the primary outcome. The RIPLS is a previously validated (Cronbach alpha $=0.90$ ) survey that assesses three domains related to IPE: teamwork/collaboration; professional identity; and roles and responsibilities. ${ }^{13} \mathrm{It}$ is available online for public use. The Likert scale for each item is scored using a point value of $5=$ strongly agree or $1=$ strongly disagree with reverse scoring on questions $10,11,12,18$ and 19 . A total score is calculated, as well as a score for each of the three domains. Scores on the primary outcome were to be compared using a paired t-test if normal distribution was found after skew and kurtosis calculations, and non-normal distributions were to be tested using the Wilcoxon signed rank test. Statistical significance was set at $p<0.05$.

Secondary outcome data was collected on student ratings of how well the activity met the learning objectives. The learning objectives for the IPE experience were provided to the students at the start of the activity. The four objectives are shown in Table 1, along with the corresponding IPEC domains. Nominal data was collected as each student rated the objective as "not at all," "somewhat," "neutral," "well," or "very well" met.

Table 1: Learning objectives and corresponding IPEC domains.

\begin{tabular}{|l|l|}
\hline \multicolumn{1}{|c|}{ LEARNING OBJECTIVE } & \multicolumn{1}{c|}{ IPEC DOMAIN } \\
\hline Compare and contrast the educational requirements of PA's and PT's. & Roles and Responsibilities \\
\hline $\begin{array}{l}\text { Compare and contrast the roles of the PA and the PT in the care of a patient } \\
\text { with the assigned condition. }\end{array}$ & $\begin{array}{l}\text { Roles and Responsibilities } \\
\text { Teams and Teamwork }\end{array}$ \\
\hline $\begin{array}{l}\text { Appropriately manage a patient presenting with the assigned condition within } \\
\text { the purview of one's own profession. }\end{array}$ & $\begin{array}{l}\text { Roles and Responsibilities } \\
\text { Teams and Teamwork }\end{array}$ \\
\hline $\begin{array}{l}\text { Appropriately document patient care in a way that clearly communicates to } \\
\text { other professions the care that was provided. }\end{array}$ & Interprofessional Communication \\
\hline
\end{tabular}

The secondary outcomes were used to determine the success of the activity and student opinion of the asynchronous format. The investigators felt that a response of "well" or "very well" would indicate successful completion of an objective because the remaining responses ("neutral", "somewhat", and "not at all") did not fall on the affirmative side of the scale. Secondary outcome data were collected during the post-activity survey. In addition, the students were asked if they preferred a live or asynchronous format for IPE activities. Since this pilot study was designed to evaluate the feasibility of online, asynchronous IPE for a future study, the investigators felt this information was also important to gather from the study participants.

\section{RESULTS}

Of the 76 eligible students who were enrolled in the IPE activity across the two cohorts, 41 students agreed to participate in the research component and completed the pre-activity assessment. Thirty-two students then completed the post-activity assessment. Fifteen students (19.7\%) completed both the pre- and post-activity assessments, for $a n n=15$ available for RIPLS response data analysis. Eleven of the sample were physical therapy students and four were physician assistant students. One participant was male. Normality testing (skew and kurtosis) was performed on the total RIPLS score and each domain using Microsoft Excel (Excel version 2004). Normal distribution was found in the total RIPLS score as well as the Teamwork and Collaboration, and Professional Identity domains. Non-normal distribution was found in the Roles and Responsibilities domain. 
There was no significant change in RIPLS score for the Teamwork and Collaboration domain, Professional Identity domain, or total score. There was a significant change in the Roles and Responsibilities score $(p=0.03)$. Table 2 outlines the pre- and post-scores for each domain as well as change score.

Table 2. Scores on the Readiness for Interprofessional Learning Survey (RIPLS) ( $n=15$ pre-and post-activity responses)

\begin{tabular}{|l|l|l|l|l|}
\hline DOMAIN & $\begin{array}{l}\text { Pre-Score } \\
\text { (mean[SD]) }\end{array}$ & $\begin{array}{l}\text { Post-Score } \\
\text { (mean[SD]) }\end{array}$ & $\begin{array}{l}\text { Mean } \\
\text { Change }\end{array}$ & p-value \\
\hline Teamwork and Collaboration & $40.20(4.54)$ & $40.13(4.50)$ & -0.07 & NS \\
\hline Professional Identity & $29.07(3.90)$ & $29.93(4.50)$ & 0.86 & NS \\
\hline Roles and Responsibilities* & $11.40(2.85)$ & $12.80(1.70)$ & 1.40 & 0.03 \\
\hline TOTAL RIPLS SCORE & $80.67(8.37)$ & $82.87(9.14)$ & 2.20 & NS \\
\hline
\end{tabular}

( $\mathrm{n}=15$, pre-and post-activity responses).

NS: not significant

* statistically significant change found

All responses on the post-activity survey were used for analysis of the objectives $(n=32)$. Twenty-two of these 32 participants were physical therapy students, and 10 were physician assistant students. Four participants were male. The majority of participants felt each objective was met. Figure 1 shows the number of students who rated each objective as "well" or "very well" met.

Compare and contrast the educational requirements of PA's and PT's.

Compare and contrast the roles of the PA and the PT in the care of a patient with the assigned condition

Appropriately manage a patient presenting with the assigned condition within the purview of one's own profession.

Appropriately document patient care in a way that clearly communicates to other professions the care that was provided.
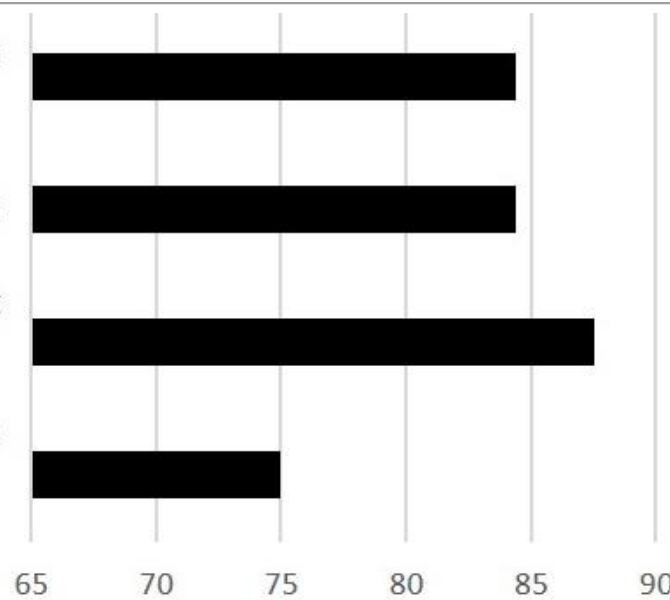

Figure 1. Percentage who felt objective was met "well" or "very well" ( $n=32)$

Participants also provided feedback on their preferred IPE delivery in the post-activity survey $(n=32)$. Figure 2 illustrates this data.

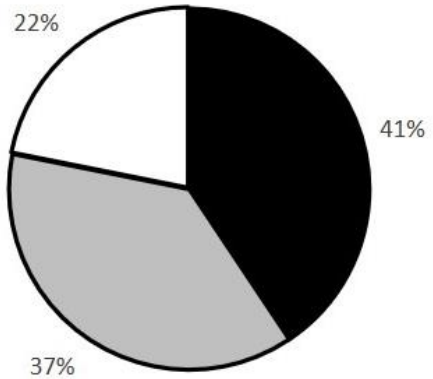

I prefer online.

ㅁ prefer live interaction.

口I'm not sure.

Figure 2. Student preference $(n=32)$ 


\section{DISCUSSION}

The primary findings are based off the pre-and post-RIPLS analyses, which used only matched pre-and post-activity scores $(n=15)$. The primary results of this pilot study suggest that the asynchronous IPE activity did not negatively impact the participants' readiness for and attitudes towards IPE as indicated by pre- and post-test responses on the RIPLS. A positive effect on the participants' beliefs about professional Roles and Responsibilities was also noted; however, this must be confirmed by further study with larger sample sizes. Additionally, there is evidence that the total RIPLS score is more reliable than the domain scores, decreasing the overall impact of this significant finding. ${ }^{14}$ Different analyses have found multiple possible sub-scales on the RIPLS, and have questioned the reliability and stability of the sub-scales; the reliability of a total RIPLS score seems universal in these studies. ${ }^{14-17}$

Previous studies on healthcare student populations have found positive changes in RIPLS scores following a live IPE activity. $18-21$ Focusing only on healthcare students, IPE activities have increased RIPLS scores following standardized patient scenarios. ${ }^{18}$ Oneday case studies and virtual-patient activities were also effective at increasing participants' RIPLS scores. ${ }^{19-21}$ Despite the use of virtual or simulated patients, the students participating in the IPE activity participated synchronously in all the above studies. Most healthcare program accreditation standards highlight the need for IPE within the curriculum, but do not account for the time restraints that quality IPE activities typically entails. ${ }^{7-12}$ At this time, there is no evidence of asynchronous IPE activities being investigated in healthcare student population. Therefore, a comparison of asynchronous and live IPE activities could add to the body of knowledge around how to implement this important component of the curriculum.

The secondary purpose of the study was to determine if the IPE activity met the pre-determined objectives. The secondary purpose only required students to complete the questionnaire at the post-activity mark, for a total sample size of $n=32$. A majority of participants rated the asynchronous activity as having "well" or "very well" met each of the four activity objectives. Since the objectives were created to reflect the domains of IPE, meeting the activity objectives was translated to mean achieving the IPEC core competencies for IPE. This is an important finding for future studies because there is currently little research on the effectiveness of asynchronous IPE. If studies continue to show that asynchronous delivery is able to meet the IPEC core competencies, then studies can proceed to determine the most effective IPE delivery method.

\section{Limitations}

The major limitation of this pilot study was the small sample size. Despite a large number of potential participants, only $19.7 \%$ of the 76 eligible students chose to submit pre- and post-activity responses. The small sample size has the potential to amplify response bias. Since the study's purpose was to examine the feasibility of asynchronous IPE, a response bias in either direction is problematic. The authors believe a major reason for the low response rate was time; the students may have seen the research participation as an extra burden to their normal classwork. The activity took place in the second half of the semester to ensure more didactic material had been covered, but this timeline placed the final data collection at the end of the semester close to the holidays and final exams. As a result, the students may have decided to use their time to study for courses in which they would be assigned a grade. In addition, the majority of responses on the pre- and post-activity questionnaires were from physical therapy students. A bias towards response from one profession could have biased the results towards that professions beliefs and experiences.

Another factor that limited the sample size was mismatched PIN's on pre- and post-activity responses. Students were instructed to write down their self-selected PIN. Despite those instructions, there was a low percent of matching pre- to post-activity PIN's. The authors interpret this as the students participated in either the pre or post assessment, or they entered an unmatched PIN for their post-activity assessment and therefore their responses were not counted. There was no way to retroactively identify which students submitted a certain response in order to protect student identities.

A second limitation to the study is the potential for a ceiling effect given the high initial RIPLS scores. The high initial scores may be a result of an introductory IPE activity that all students participated in the previous semester. Despite a potential ceiling effect, the investigators are not concerned about the high scores impacting the study purpose since the scores did not decrease following the activity. A decrease in score would have suggested the asynchronous activity negatively impacted participants' attitudes. This did not happen in any significant amount. However, the high initial RIPLS scores could explain why no positive trend was present as was found in previous studies.

The Readiness for Interprofessional Learning Scale is not the only questionnaire to evaluate response to IPE. Mahler, Berger, and Reeves challenge the individual item and subscale validity of the RIPLS. ${ }^{15}$ Other studies have found an overall acceptable validity for the total score on the RIPLS. ${ }^{13,16,17,22}$ Alternative questionnaires exist that examine other attitudes towards collaborative work 
and professional identity. The Interdisciplinary Education Perception Scale (IEPS) has approximately the same consistency and discriminatory ability as the RIPLS. ${ }^{23-35}$ Wellmon et al. found positive changes on the RIPLS, IEPS, and Attitudes Towards Healthcare Teams Scale (ATHCTS) following a single six-hour collaborative activity. ${ }^{20} \mathrm{However}$, the sensitivity of the RIPLS and IEPS to changes in score may be poor. ${ }^{24}$ Therefore, given the debated utility of the RIPLS as well as the narrow scope of focus of the questionnaire, future studies might consider utilizing more than one instrument to measure attitudes and beliefs around IPE.

Lastly, this study included students from only two healthcare professions. The IPE activity included only PA and PT students for logistical reasons; coordinating a new activity between more than two professions was deemed overreaching. However, the activity prompted the participants to explore the roles other healthcare professionals could play in managing the patient. Therefore, future studies would strengthen the results from this pilot study by including more than PA and PT students. Inclusion of the multiple professionals who would typically be involved in the patient case might create a richer learning environment for all the students involved.

\section{Future Directions}

It has been shown that asynchronous education, in general, can improve knowledge, skills, attitudes, and behaviors in healthcare education. ${ }^{26}$ Furthermore, when applied to IPE in practicing healthcare professionals, reviews showed that "e-learning" (asynchronous) was an effective way to improve knowledge and attitudes, although not necessarily skills or behaviors. 27,28 Therefore, following the successful achievement of IPE learning goals in this asynchronous environment, the investigators feel comparison of live and asynchronous IPE delivery for healthcare students is a justified future study.

\section{CONCLUSION}

The results of this pilot study suggest that an asynchronous IPE activity could be a viable alternative to traditional live activities, with positive attitudes regarding collaboration maintained during the activity and educational objectives being achieved. Future studies are needed to compare outcomes of asynchronous and live IPE.

\section{REFERENCES}

1. World Health Organization. Framework for action on interprofessional education \& collaborative practice. http://whqlibdoc.who.int/hq/2010/WHO_HRH_HPN_10.3_eng.pdf. Published 2010. Accessed August 24, 2017.

2. Schmitt M, Blue A, Aschenbrener CA et al. Core competencies for interprofessional collaborative practice: reforming health care by transforming health professionals' education. Acad Med. 2011;86(11):1351. [PMID 22030650]

3. Accreditation Review Commission on Education for the Physician Assist, Inc. Accreditation standards for physician assistant education: Standard B2.10 $5^{\text {th }}$ edition. http://www.arc-pa.org/wp-content/uploads/2019/11/Standards-5th-Ed-Nov-2019.pdf. Published September 2019. Accessed June 8, 2020.

4. Commission on Accreditation in Physical Therapy Education. Standards and Required Elements for Accreditation of Physical Therapist Education Programs: Standard 6F.

http://www.capteonline.org/uploadedFiles/CAPTEorg/About_CAPTE/Resources/Accreditation_Handbook/CAPTE_PTStandardsE vidence.pdf. Published December 17, 2017. Accessed June 5, 2020.

5. Parsell G, Spalding R, Bligh J. Shared goals, shared learning: Evaluation of a multiprofessional course for undergraduate students. Med Educ. 1998;32:304-311. [PMID A]

6. Swisher L, Woodard L, Quillen W, Monroe A. Centralized and decentralized organizational models of interprofessional education for physical therapist and medical students. J Phys Ther Educ. 2010;24(1):12-18.

7. Levy LA and Mathieson K. Attitudes of Physician Assistant Educators Toward Interprofessional Education and Collaborative Care. J Physician Assist Educ. 2017;28(2):72-79. [PMID 28437316]

8. Giordano C, Umland E, Lyons KJ. Attitudes of faculty and students in medicine and the health professions toward interprofessional education. J Allied Health. 2012;41(1):21-5. [PMID 22544404]

9. Eccott L, Greig A, Hall W et al. Evaluating students' perceptions of an interprofessional problem-based pilot learning project. J Allied Health. 2012;41(4):185-9. [PMID 23224285]

10. Saini B, Shah S, Kearey P et al. An interprofessional learning module on asthma health promotion. Am J Pharm Educ. 2011;75(2):30. [PMID 21519420]

11. Van Winkle LJ, Bjork BC, Chandar $\mathrm{N}$ et al. Interprofessional workshop to improve mutual understanding between pharmacy and medical students. Am J Pharm Educ. 2012;76(8):150. [PMID 23129849]

12. Brewer ML, Flavell HL, Jordon J. Interprofessional team-based placements: The importance of space, place, and facilitation. J Interprof Care. 2017;31(4):429-37. [PMID 28467132] 
13. Parsell $\mathrm{G}$ and Bligh J. The development of a questionnaire to assess the readiness of health care students for interprofessional learning (RIPLS). Med Educ. 1999;33(2):95-100. [PMID 10211258]

14. Williams B, Brown T, Boyle M. Construct validation of the readiness for interprofessional learning scale: A Rasch and factor analysis. J Interprof Care. 2012;26(4):326-332. [PMID 22458602]

15. Mahler C, Berger S, Reeves S. The readiness for interprofessional learning scale (RIPLS): A problematic evaluative scale for the interprofessional field. J Interprof Care. 2015;29(4):289-291. [PMID 26176984]

16. McFadyen AK, Webster V, Strachan K, Figgins E, Brown H, McKechnie J. The readiness for interprofessional learning scale: A possible more stable sub-scale model for the original version of RIPLS. J Interprof Care. 2005;19(6):595-603. [PMID 16373215]

17. Kerry MJ, Wang R, Bai J. Assessment of the readiness for interprofessional learning scale (RIPLS): An item response theory analysis. J Inteprof Care. 2018;32(5):634-637. [PMID 29648892]

18. Bethea DP, Smith N, Allison LK, Bell CS, Colins ME, Migliarese SJ, Darby R. Live standardized patient scenario improves attitudes toward and readiness for interprofessional education in occupational and physical therapy students. J Allied Health. 2019;48(2):81-87. [PMID 31167008]

19. Miller A, Morton S, Sloan P, Hashim Z. Can a single brief intervention improve participants' readiness for interprofessional learning? J Interprof Care. 2013;27(6):532-533. [PMID 23802734]

20. Wellmon R, Gilin B, Knauss L, Linn MI. Changes in student attitudes toward interprofessional learning and collaboration arising from a case-based educational experience. J Allied Health. 2012;41(1):26-34. [PMID 22544405]

21. Shoemaker MJ, de Voest M, Booth A, Meny L, Victor J. A virtual patient educational activity to improve interprofessional competencies: A randomized trial. J Interprof Care. 2015;29(4):395-397. [PMID 25412759]

22. McFadyen AK, Webster VS, Maclaren WM. Test-retest reliability of a revised version of the readiness for interprofessional learning scale (RIPLS). J Interprof Care. 2006;20(6):633-639. [PMID 17095441]

23. Sciascia A, Christopher K, Humphrey C, Simpkins L, Page CG, Jones LG. Test/re-test reliability of the readiness for interprofessional education learning scale and interdisciplinary education perception scale in health science students. J Interprof Care. 2019;18:1-10. [PMID 31852308]

24. Oates M, Davidson M. A critical appraisal of instruments to measure outcomes of interprofessional education. Med Educ. 2015;49:386-398. [PMID 25800299]

25. Lie DA, Fung CC, Trial J, Lohenry K. A comparison of two scales for assessing health professional students' attitude toward interprofessional learning. Med Educ Online. 2013;18:21885. [PMID 24300749]

26. Cook DA, Levinson AJ, Garside S et al. Internet-based learning in the health professions: a meta-analysis. JAMA.

2008;300(10):1181-96. [PMID 18780847]

27. Reeves S, Fletcher S, McLoughlin C et al. Interprofessional online learning for primary healthcare: findings from a scoping review. BMJ Open. 2017;7(8):e016872. [PMID 28780650]

28. Reeves S, Perrier L, Goldman J et al. Interprofessional education: effects on professional practice and healthcare outcomes (update). Cochrane Database Syst Rev. 2013(3):CD002213. [PMID 23543515]

\section{APPENDIX 1}

The Readiness for Interprofessional Learning Survey (RIPLS)

\begin{tabular}{|l|l|l|l|l|l|l|}
\hline & & $\begin{array}{l}\text { Strongly } \\
\text { Agree }\end{array}$ & Agree & Undecided & Disagree & $\begin{array}{l}\text { Strongly } \\
\text { Disagree }\end{array}$ \\
\hline $\mathbf{1 .}$ & $\begin{array}{l}\text { Learning with other students / professionals will } \\
\text { make me a more effective member of a health and } \\
\text { social care team. }\end{array}$ & & & & \\
\hline $\mathbf{2 .}$ & $\begin{array}{l}\text { Patients would ultimately benefit if health and } \\
\text { social care students / professionals worked } \\
\text { together. }\end{array}$ & & & & & \\
\hline $\mathbf{3 .}$ & $\begin{array}{l}\text { Shared learning with other health and social care } \\
\text { students / professionals will increase my ability to } \\
\text { understand clinical problems. }\end{array}$ & & & & & \\
\hline $\mathbf{4 .}$ & $\begin{array}{l}\text { Communications skills should be learned with } \\
\text { other health and social care students / } \\
\text { professionals. }\end{array}$ & & & & & \\
\hline
\end{tabular}

(C) The Internet Journal of Allied health Sciences and Practice, 2021 


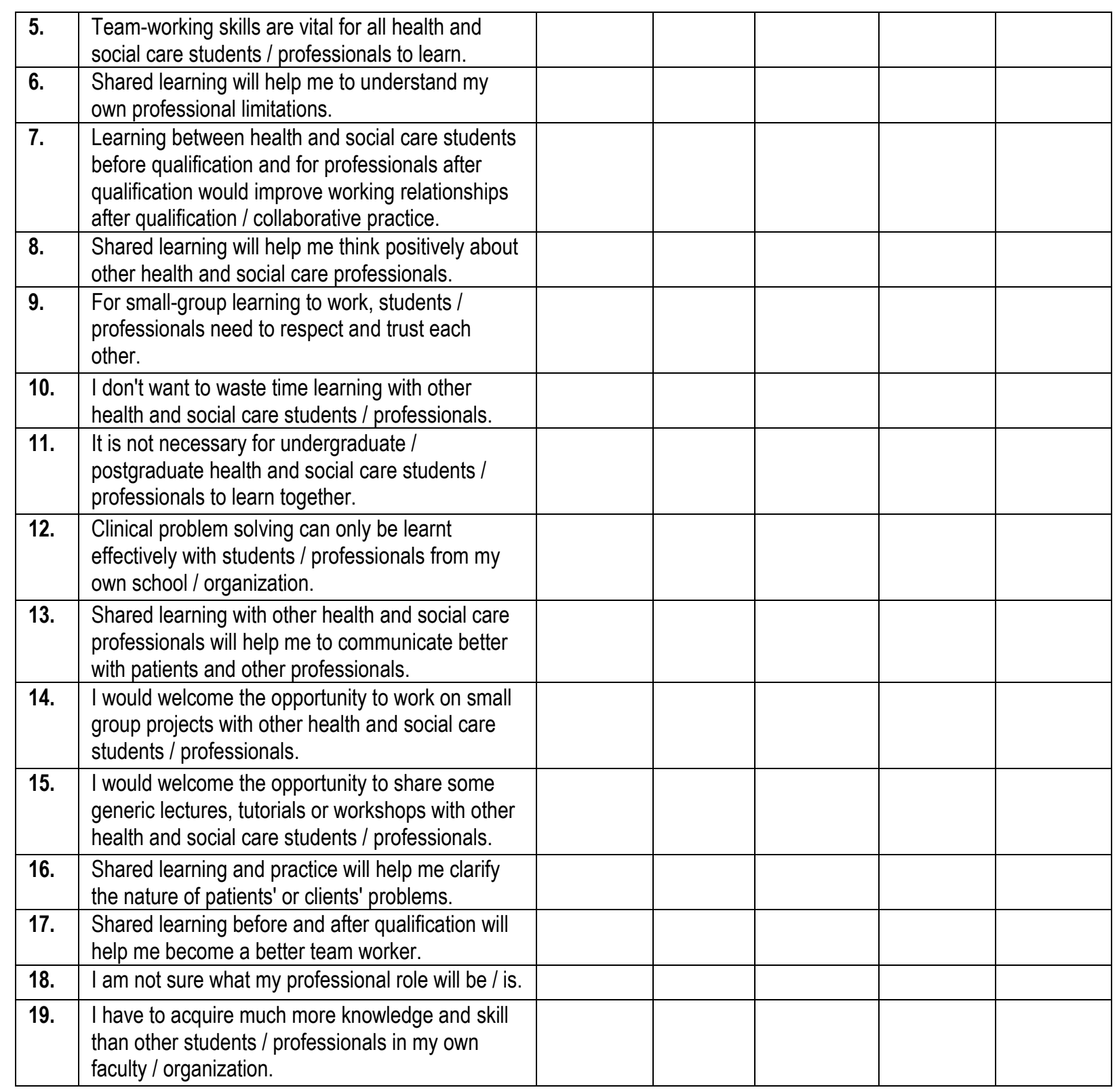

